\title{
A intuição como fundamento do ensino das artes em tempos de revisão paradigmática
}

\section{Intuition as a fundamental of Art Education in times of paradigmatic revision}

\author{
Alexsandro dos Santos Machado ${ }^{i}$ \\ Universidade Federal do Vale do São Francisco \\ Hugo Monteiroii \\ Universidade Federal Rural de Pernambuco
}

\section{Resumo}

Este artigo propõe reflexões sobre a intuição como fundamento do ensino das artes em tempos de revisão paradigmática. Situa o leitor, em termos históricos, quando do advento do chamado método intuitivo, ao tempo que traz à tona discussões sobre as bases epistêmicas que tornam a intuição uma espécie de matriz para um método que põe as artes como elemento fulcral dos processos escolares. Aqui, a intuição é tratada como o chão transdisciplinar no qual se edifica uma nova ordem para saberes.

\section{Palavras-chave}

Intuição - Escola - Fundamentos das Artes - Revisão Paradigmática

\section{Abstract}

This article presents reflections on intuition as the basis of Art Education in times of paradigmatic revision. It situates the reader historically, from the so-called intuitive method to the times that bring up discussions about the epistemic bases that make intuition a kind of blueprint for a method that places the arts as a core element of school processes. Here, intuition is treated as disciplinary ground on which a new order of knowledge is built.

Keys-word

Intuition - School - Fundamentals of Arts - Paradigmatic revision

\section{Introdução}

Não são palavras: são reflexões que nascem de uma prática escolar, de uma luta político-cultural, do empenho e da experimentação de anos. Não são receitas: são a conquista de uma nova posição, de um papel diferente. E é claro que, a esta altura, infinitos problemas aparecem para serem resolvidos pelos professores. Mas entre uma escola morta e uma escola viva, o discriminante mais autêntico é exatamente este: a escola para "consumidores" está morta, e fingir que está viva só retarda a putrefação (que todos percebem); uma escola

Revista Digital do LAV - Santa Maria - vol. 8, n. 2, p. 118 - 142. - mai./ago. 2015 ISSN 1983 - 7348

http://dx.doi.org/10.5902/1983734819868 
viva e nova pode ser apenas uma escola para "criadores". É como se nela não existissem "escolares" e "professores", mas homens inteiros. (RODARI, 1982, p. 143)

"A escola para 'consumidores' está morta." Há mais de quarenta anos esse atestado de óbito fora lavrado por Gianni Rodari em sua magnífica obra "Gramática da Fantasia". Todos já percebiam. Todos percebemos. Todavia, enredados que estamos em um contexto hiper-capitalista (BIFO, 2007), erigimos um mausoléu à escolamúmia. É consenso de todos que a escola é uma instituição importante, embora seja também igualmente consensual a opinião de que seu modelo esteja falido. Assim, sem conseguir dar vazão à intuição e ao elán vital ${ }^{1}$ que se evidenciam nos corpos dos que vivem e fazem a escola, a mumificamos para retardar ainda mais seu processo de putrefação. Há, sem dúvida, uma série de processos escolares, facilmente constatados pelo discurso, que enredam a vida da escola em invólucros mumificantes. Porém há uma escola viva que se debate dentre as faixas de mumificação. O elán vital busca vida íntegra e plena em todas as direções e formas. Os corpos das crianças e dos professores buscam movimento em meio aos processos mumificantes. A escola tornou-se uma múmia que caminha. Contudo, várias faixas vão ficando pelo caminho e, se observarmos com atenção, perceberemos que a múmia já está ensaiando alguns passos de dança...

Por meio deste artigo nos propomos a tecer uma reflexão teórica acerca da Intuição como fundamento do Ensino das Artes. Potencializado pelo método Intuitivo, imbuído de uma abordagem transdiciplinar, o Ensino das Artes pode fomentar a percepção e

\footnotetext{
${ }^{1}$ Élan Vital é um termo bastante característico da filosofia de Henri Bergson. É por meio de sua obra Evolução Criadora, de maneira especial, que o filósofo desenvolve a sua teoria da evolução, no qual o "élan original da vida" ocupa local central. Tal teoria da evolução bergsoniana insiste em um impulso vital que marca todo ser vivo. O Élan Vital é a energia que impulsiona a recriação e a evolução de todas as formas de vida. Pode-se compreender Elán Vital como um vento de vida que "irrompe em uma encruzilhada dividindo-se em correntes divergentes, que são todas apenas um único e mesmo sopro" (BERGSON, 2005, p.55). Trata-se de um movimento de diferenciação e de criação da vida, concebendose "a diferenciação nunca como uma negação, mas uma criação, e a diferença nunca como negativa, mas essencialmente positiva e criadora" (DELEUZE, 1999, p.82).
}

Revista Digital do LAV - Santa Maria - vol. 8, n. 2, p. 118- 142. - mai./ago. 2015 ISSN 1983 - 7348 http://dx.doi.org/10.5902/1983734819868 
a criação estéticas de maneira que contribua na (Re) criação de uma escola mais viva.

Para tanto, iniciaremos apresentando o Método Intuitivo na História da Educação brasileira (especialmente no fim do século XIX e início do século XX). Também refletiremos sobre o conceito de intuição, especialmente a partir da obra de Henri Bergson. Aprofundando essa reflexão, abordaremos uma distinção entre rigor e rigidez na educação escolar contemporânea. Tal distinção será importante para evidenciarmos alguns desafios para um método intuitivo no Ensino das Artes em nosso contexto educativo atual. Abordamos essa problemática, de maneira especial, por meio da literatura e da dança. Por fim, concluiremos como a Intuição como fundamento do Ensino das Artes pode contribui para a (re) criação da escola.

\section{A intuição e o método intuitivo na Educação brasileira}

Em meados do século XIX, o método intuitivo é apresentado por pesquisadores europeus como "instrumento pedagógico capaz de reverter a ineficiência do ensino escolar". (VALDEMARIN, 2014a, p.86) Tal ineficiência é evidenciada pelos novos desafios sociais e econômicos daquele tempo, especialmente pela necessidade de um raciocínio mais rápido e criativo dos trabalhadores da indústria emergente.

"Intueri, olhar; intuitus, observação" poderia ser a síntese metodológica dessa abordagem. O método inuitivo, também conhecido sob a denominação de lições de coisas, têm por objetivo educar os sentidos para obtenção do conhecimento, de modo que passe da intuição dos sentidos para a intuição intelectual. Fazendo uso de objetos didáticos, conhecidos ou semelhantes àqueles conhecidos pelos alunos, esse método objetivava, de uma forma concreta, racional e ativa, promover aprendizagens cada vez mais complexas a partir da observação e interpretação do mundo. (VALDEMARIN, 2014a; VALDEMARIN, 2014b).

No Brasil o método intuitivo é divulgado nas últimas décadas do século XIX e fomentado, de maneira especial, a partir dos pareceres de Rui Barbosa em vista da reforma educacional do final do século XIX. Empolgado com as potencialidades do método intuitivo e seus alcances educativos e sociais, Rui Barbosa também traduz a

Revista Digital do LAV - Santa Maria - vol. 8, n. 2, p. 118 - 142. - mai./ago. 2015 ISSN 1983 - 7348 http://dx.doi.org/10.5902/1983734819868 
obra Primeiras lições de coisas de Norman Allison² (VALDEMARIN, 2000; VALDEMARIN, 2004). As ideias, práticas e dispositivos vinculados ao método intuitivo foram irradiadas pelo país segundo demonstram alguns estudos comparativos (VALDEMARIN, TEIVE \& HAMDAN, 2013). Todavia, outras pesquisas apontam pela dificuldade da implementação da proposta por conta da carência de material didático, carência professores habilitados e carência de direcionamento político para a educação popular. (SOUZA, 2009)

Pode-se afirmar que o método intuitivo, ou lições de coisas, são exemplos do pensamento caracterizador do século XIX, "o tempo das certezas" (VALDEMARIN, 20148, p.170). Naquele contexto, o conteúdo escolar é estabelecido em continuidade com episódios cotidianos, tendo a natureza como objeto a ser compreendido, classificado, transformado em favor da sobrevivência e conforto da humanidade. Tal visão moderna, que tem como base a filosofia igualmente moderna de Francis Bacon e John Locke (VALDEMARIN, 2014a, p.84), apresenta a escola como instituição imersa numa concepção utilitária da ciência e da arte.

O desenho, por exemplo, era caracterizado como uma das atividades essenciais ao método intuitivo. Todavia, era compreendido especialmente a partir de suas aplicações artísticas e industriais. Além de um conteúdo particular, o desenho também era tido como uma estratégia de verificação da aprendizagem de praticamente todos os conteúdos (VALDEMARIN, 2014a, p. 91). Trata-se, portanto, de uma visão predominantemente utilitarista da arte na escola.

Nesse sentido, desde o final do Século XIX os precursores escolanivistas já discutiam a inauguração de uma nova era na Educação brasileira. A Escola Nova, porém, desqualificava todas as conquistas da educação nas quase quatro décadas do início da república brasileira (VEIGA, 2000). Embora o movimento escolanovista não possa ser compreendido como homogêneo em seus princípios, a Escola Nova, em seu discurso preponderante, enfatizou de maneira dicotômica dois modelos de escolarização: Escola Tradicional X Escola Nova (NUNES, 1996). Ao opor a Escola

\footnotetext{
${ }^{2}$ O livro Primeiras Lições de coisas: manual de ensino elementar para uso dos paes e professores foi escrit por Norman Allison e apresentado na Exposição Universal da Filadélfia em 1876. Rui Barbosa o traduziu em 1886. Em 1950 o texto é republicado pelo Ministério da Educação e Saúde, no volume 13 das Obras Completas de Rui Barbosa.
}

Revista Digital do LAV - Santa Maria - vol. 8, n. 2, p. 118- 142. - mai./ago. 2015 ISSN 1983 - 7348 http://dx.doi.org/10.5902/1983734819868 
Tradicional versus a Escola Nova, o movimento escolanovista reservou ao passado recente "tradicional" o estigma de pior o que havia na educação. Em miúdos, como é comum em análises dicotômicas simplistas, se jogou a criança pela janela junto com a água suja do banho.

Tomando como referência o pensamento de John Dewey, o pensamento da Escola Nova substituiu a intuição pelo problema, isto é, o conhecimento resultaria a partir da indagação geradora da reflexão. Todavia, segundo VALDEMARIN (2014b), um dos resultados dessa mudança de foco metodológico foi o deslocamento da função de transmissão cultural dos professores para um segundo plano. Tal deslocamento levou a uma consequência epistemológica: a elaboração do saber, até os dias de hoje, parece se restringir prioritariamente a listas de conteúdos, guias curriculares, textos legais e livros didáticos.

Nesse sentido, em tempos de revisões paradigmáticas, imersos em um novo contexto de crises recorrentes nos sistemas de ensino, conscientes que estamos dos desafios de se Educar em tempos incertos (ENGUITA, 2007), nos questionamos: teria a intuição função e espaço de revisão epistemológica e (re) criação da escola? Ou ainda, o que entenderíamos por uma Pedagogia da Intuição em nosso tempo?

Em sua tese de doutorado intitulada Intuições para uma Pedagogia da Intuição: a amizade enquanto uma experiência integral pela Dinâmica das Cartas, MACHADO (2012), analisa as reações de um grupo de ex-estudantes ao ler suas próprias cartas endereçadas a eles mesmos há cinco anos. Ao ouvirem suas próprias vozes do tempo do ensino médio os jovens ${ }^{3}$ refletem sobre os objetivos e os sentidos da Educação. De maneira especial, respondem a pergunta: "O que dura da Educação?" Constatouse por meio dos relatos escritos e entrevistas realizadas junto aos participantes da pesquisa que não havia um único relato de agradecimento à habilidade de ler, escrever, contar ou de saber utilizar fórmulas de física, química em seus trabalhos atuais. Os relatos faziam referência, em sua imensa maioria, às relações humanas

\footnotetext{
${ }^{3}$ Os 38 participantes da referida pesquisa tinham entre 14 e 17 anos em 2003, quando redigiram suas cartas. Ao receberem suas próprias cartas invioladas em 2008 tinha, portanto, entre 19 e 22 anos.
}

Revista Digital do LAV - Santa Maria - vol. 8, n. 2, p. 118 - 142. - mai./ago. 2015 ISSN 1983 - 7348 http://dx.doi.org/10.5902/1983734819868 
(especialmente às amizades) e um conhecimento construído de forma intuitiva e afetiva ao longo da vida.

Haja vista tais constatações, Machado recorre então aos conceitos de Duração e Intuição em Henri Bergson. Ainda no início do século XX Bergson combatia uma espécie de "intelectualismo" ao contrapor intuição e inteligência. Em linhas gerais, o autor afirmava que a intuição é a faculdade mais capaz do conhecimento verdadeiro (NEVES, 1994, p. 29-30). O conhecimento pode ser gerado mediante a intuição e pela inteligência. Ambos processos estão presentes no cotidiano escolar. Agregar essas duas dimensões tavez seja o esforço metodológico principal para integrar a experiência humana por meio da educação (MACHADO, 2013, p.17) E, ao nosso ver, é por meio de uma ótica intuitiva que poderemos compreender a educação como um processo de (re) criação da vida.

A propósito, é por meio de uma metodologia que privilegia a intuição que poderemos conceder à Arte seu status poético-educativo pois, como disse Bergson (2005, p7)

\begin{abstract}
Ninguém, nem mesmo 0 artista, poderia ter previsto exatamente o que seria o retrato, pois predizê-lo teria sido produzi-lo antes que fosse produzido, hipótese absurda que se destrói a si mesma. O mesmo vale para os momentos de nossa vida, dos quais somos artífices. Cada um deles é uma espécie de criação. E, assim, como o talento do pintor se forma ou se deforma, em todo o caso se modifica, pela própria influência das obras que produz, assim também cada um de nossos estados, ao mesmo tempo que sai de nós, modifica nossa pessoa, sendo a forma nova que acabamos de nos dar. Temse portanto razão em dizer que o que fazemos depende daquilo que somos; mas deve-se acrescentar que, em certa medida, somos o que fazemos e que nos criamos continuamente a nós mesmos. Essa criação de si por si é tanto mais completa, aliás, quanto melhor raciocinamos sobre o que fazemos.
\end{abstract}

Nesse sentido, adiante apresentaremos uma reflexão acerca de uma educação escolar sob uma ótica intuitiva que nos possibilite transcender o paradigma cartesiano de uma escola moderna no sentido de uma escola mais viva.

\title{
A educação escolar sob a ótica intuitiva: rigor e rigidez
}

Revista Digital do LAV - Santa Maria - vol. 8, n. 2, p. 118- 142. - mai./ago. 2015 ISSN 1983 - 7348 http://dx.doi.org/10.5902/1983734819868 
Falemos de uma educação escolar menos moderna, no que a modernidade possui de reducionista, e tratemos de uma educação escolar fundamentada em pressupostos e princípios baseados nos três pilares que sustentam uma compreensão e uma explicação transdisciplinar do real e da realidade. A diferença central existente entre essas duas escolas, a reducionista e a, digamos, não-reducionista, talvez seja o que aqui nominamos como aquela forjada sob a "ótica intuitiva".

A "ótica intuitiva" mais do que se diferenciar de uma "ótica não-intuitiva" procura possibilitar tanto ao sujeito da observação quanto ao objeto observado, reflexões que se ampliam em relação aos processos instaurados a partir da intenção de se compreender e explicar a verdade, por conseguinte o verdadeiro. A "ótica intuitiva" almeja ver além do previsto, do prescritivo, do a priori, do já estabelecido, do já dito, do predeterminado. É uma ótica filigrânica sem ser descritivista.

A educação escolar sob a ótica da intuição não se referencia nos parâmetros restritos do método cartesiano e nem se reduz aos modelos engendrados pelas teorias positivistas dos séculos ultraracionalistas. A intuição, assim como a entendeu, Johan Huizinga, em seu livro Homo Ludens (2000), favorece a evocação e as tratativas do lúdico como forma de compreensão e reflexão em torno da vida e de seus desdobramentos.

As problemáticas que se instauram numa escola quando os fundamentos que a regem estão menos atrelados ao lúdico e mais atrelados ao não-lúdico talvez sejam as mesmas que ocorrem no instante em que a escola, na sua condição social e histórica, opta pela negação da intuição como mecanismo de se entender e se explicar o cotidiano da sala de aula, portanto das práticas pedagógicas que se dão nos bancos escolares e entre os atores que ali estão.

A negação da intuição como uma das faculdades humanas capaz de gerar, socializar e propor conhecimentos é certamente a negação da natureza simbólica do ser humano. Negar, nesse caso, é menos dizer que não existe e mais designar uma função e um papel de menor valor ou de valor meramente figurativo. A negação da simbólica como forma de acesso ao conhecimento científico foi realizada pela humanidade ocidental de modo engenhoso.

Revista Digital do LAV - Santa Maria - vol. 8, n. 2, p. 118 - 142. - mai./ago. 2015 ISSN 1983 - 7348 http://dx.doi.org/10.5902/1983734819868 
A ideia moderna que explicitou a matematização da vida como sendo a legítima e única maneira de ser ter a verdade representada ou a representação da verdade num grau passível de aceitação lógica é responsável pela inutilidade da intuição no que diz respeito à construção de saberes científicos. Isto porque, há um entendimento sobre a matemática que torna esse tipo de conhecimento mais valioso se comparado a outros que não se the assemelham.

A escola moderna - ou a escola forjada no pensamento burguês - soube, de maneira quase biunívoca, assimilar esse ideário que outorga à matemática a condição de disciplina regente dos saberes científicos e outorga à intuição a condição de faculdade humana com pouca - ou quase nenhuma serventia - para a construção de saberes necessários ao mercado e ao discurso importo pelas regras do mercado. A escola moderna, nesse sentido, não cuidou devidamente da intuição.

Esse não cuidado devido da intuição, no caso da escola moderna, tem vários desdobramentos, desde os mais simples aos mais complexos. Como exemplo dos mais simples - ou aqueles mais tangíveis - é possível que falemos sobre a construção arquitetônica das escolas e suas instalações excludentes e reservadas a condições humanas ditas como produtivas. A exemplo do mais complexo, podemos ilustrar com a fenomenologia bullying e a rejeição identitária.

No nosso entendimento, a recusa à intuição é a recusa à simbólica, é a recusa à imaginação, logo é a recusa aos saberes que não se matematizam e nem são por essa lógica legitimados. A escola moderna entendeu que conhecimento sério e valioso só era tão-somente aquele possível de ser "rigorosamente" testado pelas regras matemáticas, aritméticas, geométricas e algébricas. Saberes que não se dessem a tais processos, seriam secundários.

Certamente, os saberes construídos na escola moderna foram engendrados conforme preconizavam as regas do método científico cartesiano. Isto porque foram essas regras que consolidaram o pensamento ultraracionalista que presenciamos em muitas correntes teóricas principalmente nos séculos XVII, XVIII e XX. A ideia de rigor científico advém dessa lógica: tudo deve ser analisado e verificado sob a ótica da lógica dos cálculos.

Revista Digital do LAV - Santa Maria - vol. 8, n. 2, p. 118- 142. - mai./ago. 2015 ISSN 1983 - 7348 http://dx.doi.org/10.5902/1983734819868 
A lógica dos cálculos - ou aquela que faz com que quase toda a filosofia grega se mantenha viva e atuante até os dias contemporâneos - propõe que a verdade não seja jamais alcançável, exceto se o seu observador for capaz de equacioná-la de modo numérico e legível. A tentativa de torna real a verdade por meio de lógica binária e estatística, no entendimento da escola moderna, é fundamental para que o conhecimento escolar tenha sentido e funcionalidade.

Uma produção de conhecimento funcionalista necessita ser uma produção de saberes que tenham função num mundo regido pela ideia de funções. A matemática e seu suposto rigor é alçada a patamares altíssimos, fazendo com que todas as outras lógicas - a que se inclui a intuitiva - que não seguem a matematização da realidade, perca força quando instaurada dentro do ambiente escolar e nas suas variações pedagógicas.

O rigor dito científico tem fundamento em tentar fazer com que o sujeito da observação evite ultrajar o objeto observado com as suas fragilidades humanas. As fragilidades humanas a que se refere o rigor científico são várias e diversas, pois a subjetividade é motivo sempre de erros e de equívocos, visto que o ser humano, por meio de suas impressões, pode - e certamente assim fará - distorcer o objeto observado. O rigor científico, portanto, pode ser resumido: a desumanização da observação.

Desumanizar a observação do fenômeno é retirar da relação observador e realidade observada toda e qualquer ideia de intimidade. A distância mental é a meta para que o rigor ocorra. A rigorosidade buscada é uma tentativa orquestrada de se evitar desvios e imprecisões, transgressões e incertezas, impropriedades e inquietações. É uma tentativa de fazer com que nada saia dos trilhos previamente ordenados, milimetricamente propostos.

Eis, no nosso entendimento, uma tentativa frustrada, posto que é delusória. Acreditar na rigorosidade científica como sinônimo de dicotomia sujeito observador e objeto observado é acreditar que a invenção da ciência não é invenção da mente humana, logo não é produto de ideologias e de interesses humanizados. A ideia de separar o

Revista Digital do LAV - Santa Maria - vol. 8, n. 2, p. 118 - 142. - mai./ago. 2015 ISSN 1983 - 7348 http://dx.doi.org/10.5902/1983734819868 
sujeito observador do objeto observado e de dividir o objeto em pequenas partes para que a compreensão de seu todo seja realizado, também é humana.

Ou seja, o rigor almejado e objetivado nada mais é do que um tipo de rigor, entendemos que um rigor equivocado e pouco realizável. Nem mesmo nos chamados fenômenos matemáticos esse rigor se realiza. A matemática, como bem explica Castoriadis (2007), é pura criação imaginária e só se torna real de fato quando é entendida no campo mais fantasioso de sua criação. Qualquer tentativa de estabelecer um rigor tomado pela regra da separação e da fragmentação é menos rigor, e mais rigidez.

A rigidez é péssima para a construção dos saberes, visto que é limitante e limitada, radical e discriminadora. A rigidez científica nada tem de inteligente, posto que é demasiadamente dogmática. A dogmatização do rigor é um perigo para a escola. Lamentavelmente, durante as teorias ultraracionalistas, houve um equívoco e se confundiu rigor com rigidez, conhecimento com matemática, lógica com cálculo, ciência com religião.

A rigidez científica desconsidera o que Maffesoli, em seu livro Elogio da Razão Sensível (2005), nomina de conhecimento incorporante. Ou seja, um tipo de conhecimento que não nasce exclusivamente da matematização do saber, porém se materializa desde as conversas triviais do cotidiano até as mais sofisticadas teorias mecatrônicas. A rigidez é o excesso de regra onde deve necessariamente haver a não-regra.

Uma escola rígida não é uma escola melhor do que uma escola flexível. De um ponto de vista dos ensinos e das aprendizagens, os modelos pedagógicos tradicionalistas, severamente criticados pelos modelos sócio-históricos, dão demonstração das repercussões da rigidez em detrimento da flexibilidade. Entendemos que a ótica intuitiva, considerando que sua matriz de existência, não é necessariamente a matriz exclusivamente racionalista, é bastante rigorosa.

O rigor a que nos referimos não se assenta na poltrona da exclusividade, mas se assenta nos espaços das integrações e das transdisciplinaridades. Em outras palavras, o rigor intuitivo, ao contrário da rigidez racionalista, não nega ou 
menospreza a existência da segunda, mas a explica de modo que fique evidente seu grau de alcance e suas limitações epistemológicas, conceituais, teóricas e metodológicas.

Morin (2000, p.149), acredita que a intuição é muito rigorosa na construção de sentidos. Mais do que isso, a intuição possui um papel enorme: ser o motor do conhecimento. Todavia, tal papel "não se pode colocar em fórmulas matemáticas". Parafraseando Morin, poderíamos afirmar que a intuição também é motor da produção artística e do Ensino da Arte. Mas seria possível colocar a intuição em uma tela? Seria possível escupi-la ou dançá-la?

Bergson (1994, p. 27) explica a Intuição Filosófica como " algo de simples, de infinitamente simples, de tão extraordinariamente simples que o filósofo nunca conseguiu dizê-lo. E é por isso que ele falou toda a sua vida." A intuição se revela como um dado imediato da consciência de maneira simples, mas com tamanha complexidade que poderíamos explicá-la até o infinito. Trata-se de um conhecimento para "o interior mesmo da vida" (BERGSON, 2005, p.191).

Sendo assim, precisamos situar melhor a problemática da relação da intuição e do Ensino de Arte. Reconhecendo que a intuição seja o motor da ciência, da filosofia e da arte, e dada a impossibilidade de mensurá-la ou exprimi-la, nosso esforço não reside em encontrar uma "metodologia intuitiva" para o Ensino das Artes, mas de reconhecer na Intuição um fundamento do Ensino das Artes.

\section{Uma prática pedagógica intuitiva e o ensino das artes: o caso da literatura e da dança}

Vimos, ao longo dos tópicos 1 e 2 argumentos que nos levam à seguinte conclusão: há uma relação muito profícua entre o ensino das artes e as bases de um modelo de escola fundamentado numa perspectiva intuitiva ou numa ótica intuitiva. Não se trata, portanto, de encontrarmos técnicas e atividades intuitivas para o Ensino das Artes, mas de educar a sensibilidade dos professores e estudantes a fim de que se permita o fluxo do elan vital por meio da Intuição.

Revista Digital do LAV - Santa Maria - vol. 8, n. 2, p. 118 - 142. - mai./ago. 2015 ISSN 1983 - 7348 http://dx.doi.org/10.5902/1983734819868 
Desse modo, quando consideramos o ensino das artes e, ao mesmo tempo, consideramos a prática pedagógica, precisamos verificar como o ensino das artes se relaciona com as variáveis que constituem a prática em sala de aula.

Ensinar artes em uma escola pode ser um trajeto repleto de possibilidades. A natureza transdisciplinar das artes conduz o mediador da aprendizagem ao um nível de reflexão que Ihe importa uma postura pedagógica reflexiva. As artes, assim como a entendemos, invenção humana cuja essência tem a ver diretamente com a demência e a ludicidade do homo demens sapiens, se escolarizada sob a ótica de hermenêuticas exclusivamente disciplinares, tenderá a perder seu viço.

As artes como uma disciplina escolar, portanto as artes inseridas nos processos de ensino e de aprendizagem, podem ser vivenciadas no seu grau mais plural ou no seu grau mais singular. Queremos dizer com isso, que a vivência das artes na escola pode ocorrer fundamentada numa espécie de lógica racionalista, para a qual as artes não são senão artificio de segunda ordem, adereço de currículo, moldura para quadro, experiência da frivolidade, dispensável nas coisas realmente sérias.

Ou pode ocorrer de outro modo, sob a ótica da intuição, para a qual, as artes não são senão essencial. No âmbito do ensino intuitivo ou ensino baseado em discussões transdisciplinares, as artes não somente são o chão para a construção de edifícios cognitivos, porém são lastros para a construção dos demais edifícios componentes das diversas psicologias humanas. Em outras palavras, as artes são a base do ensino e não o acessório.

Nesse sentido, as variáveis que compõem a prática pedagógica, quando fundamentadas numa perspectiva intuitiva, mudarão sua razão de existir em sala de aula ao passo que repercutirão de modo diferente nos processos de ensinos e de aprendizagens. Como sabemos existem muitas linguagens artísticas importantes para os processos escolares. Em nosso caso, para efeito de argumentos, nos deteremos em duas: a literatura e a dança.

Revista Digital do LAV - Santa Maria - vol. 8, n. 2, p. 118- 142. - mai./ago. 2015 ISSN 1983 - 7348 http://dx.doi.org/10.5902/1983734819868 
O ensino da literatura nem sempre respeita a literatura. De modo geral, é um ensino cujo objetivo maior é menos o literário e mais o arranjo linguístico que se dá na formação do objeto artístico. É um ensino menos preocupado com a leitura em si mesma e mais preocupado com os arremedos técnicos que estão presentes em um dado texto literário. Por exemplo, é comum que crianças aprendam literatura aprendendo história e aprendam a ler textos aprendendo dados biográficos.

Quando pensamos o ensino da literatura nas escolas, entendemos que esse ensino deva respeitar este objeto artístico e todas as suas nuances. Uma das principais características do literário é a polissemia, a pluralidade de sentidos, a variedade de significados. A literatura é um objeto artístico que se ensinado como arte tenderá a trazer para o centro da sala de aula uma reflexão profunda e importante sobre a condição humana e seus valores.

No entanto, para que o ensino da literatura seja realizado em sala de aula do modo como aludimos acima, é necessário que as variáveis que compõem a prática pedagógica tenham, digamos, sustentação numa compreensão de ensino e de aprendizagem fundamentada em matrizes epistêmicas não redutoras. Ou naquilo que no tópico 2 nominamos como ótica intuitiva. É necessário dizer que a palavra ótica tem, nesse caso, sinonímia com a palavra paradigma ou mesmo com a expressão visão de mundo.

Dessa maneira, é essencial que as variáveis constitutivas da prática pedagógica, portanto a própria prática, estejam coadunando com um tipo de matriz epistêmica que em nada se reduza a meros achaques positivistas. A literatura, quando inserida na escola de modo reflexivo, certamente não se submeterá a reduções pedagógicas. No entanto, se o ensino da literatura não estiver em sintonia com a natureza do objeto, o próprio objeto poderá ser, digamos, reduzido.

Nesse caso de redução da sua potencialidade artística, a literatura pode se tornar uma espécie de instrumento de ensino, porém um ensino pouco reflexivo e bastante restrito a informações superficiais. Para que isso não se dê desse modo, entendemos que seja relevante que a literatura esteja presente no planejamento de ensino, no

Revista Digital do LAV - Santa Maria - vol. 8, n. 2, p. 118 - 142. - mai./ago. 2015 ISSN 1983 - 7348 http://dx.doi.org/10.5902/1983734819868 
currículo escolar e nos processos avaliativos, no seu fulgor da língua e da linguagem, na sua polifonia e na sua polissemia.

De outro modo, a escolarização do literário certamente não considerará o ensino e aprendizagem fundamentados em lógicas não matematizáveis. A intuição, nesse caso, como método para o ensino das artes, mais precisamente, como método para o ensino da literatura, deverá ser usada menos como uma possibilidade e mais como uma matriz metodológica que dará ao planejamento de ensino rigor flexível. Isto quer dizer dialogicidade e contextualização.

O ensino do literário, se feito sob a ótica da intuição, não se restringirá a demandas historicistas e nem a demandas biográficas, mas levará o aluno a refletir sobre a condição humana tratada e discutida pelo objeto artístico, promovendo e possibilitando reflexões para além do tão-somente escolar. A escola, nesse caso, ajudará na formação do leitor literário e na melhoria da socialização do conhecimento advindo da leitura desse objeto artístico.

Um currículo amparado em bases intuitivas certamente não será um currículo excludente e redutor, mas uma variável da prática pedagógica organizada de maneira plural e includente, contextual e dialógica, interdisciplinar e transdisciplinar. Um currículo integrado e integrante. Nessa compreensão curricular não cabe a hierarquização como modelo e nem a classificação como mote para separar o que é relevante do que não é relevante.

Sob a ótica de um rigor intuitivo, o currículo escolar se aproxima muito de uma compreensão curricular pós-crítica para a qual a compreensão tradicionalista tem fragilidades as quais necessitam ser revisitadas. O papel do texto literário numa sala de aula onde o currículo seja dinâmico, como quer Demo (2011), é também de conectar disciplinar, funcionando como uma espécie de fio condutor, ligando as convergências e as divergências disciplinares.

Nesse sentido, se a compreensão sobre o currículo escolar na prática pedagógica não for aberta, digamos assim, o texto literário muito provavelmente será mero artificio

Revista Digital do LAV - Santa Maria - vol. 8, n. 2, p. 118- 142. - mai./ago. 2015 ISSN 1983 - 7348 http://dx.doi.org/10.5902/1983734819868 
de ensino ou um ensino demasiadamente prescritivo. É relevante que se diga que a prescrição, nesse caso, só tende a reduzir as reflexões necessárias sobre a realidade complexa na qual o estudante e a estudante estão inseridos. Ou seja, uma realidade de pouca valia para a vida real.

Assim como a literatura deve ser escolarizada de maneira que sua natureza eminentemente artística não seja reduzida a maneirismos pedagógicos, parece-nos que a dança deve seguir caminho igual. Evidente que há diferenças entre as duas linguagens, mas a natureza artística de ambas parece que necessita ser compreendida pela prática pedagógica, com vistas a não termos o uso da dança na escola, como mero recurso de lazer, enfeite para eventos sazonais e espetáculos realizados para jogos escolares.

O papel da dança em sala de aula remete à relevância do corpo, à ideia de corporeidade integrada à mente. Conhecimento não é só da ordem do mental, mas é sobremaneira da ordem do corporal. Essa é uma questão relevante para o ensino das artes numa perspectiva não redutora. Mas uma vez ressaltamos que a expressão "não redutora" tem rede sinonímica com a expressão "ótica intuitiva". Nesse sentido, o ensino da dança na escola não deve ser tido como algo irrelevante para o saber.

Ou para os saberes. A dança, quando escolarizada de maneira adequada, digamos assim, ocupa uma dimensão nos bancos escolares que permite aos atores escolares vivenciar experiências significativas para o saber. Strazzacappa (2002/2003) entende que a dança na escola evoca discussões curriculares não frequentes nas salas de aulas. Essas discussões, sobre as quais trata essa autora, são de natureza intuitiva ou de natureza não matematizável.

A dança na sala de aula permite ao docente colocar no centro da discussão temas relevantes para a construção de saberes que necessariamente nem sempre são discutidos pelas escolas em suas seleções de conteúdos. A dança, uma vez que mexe com a corporeidade, mexe com a construção de sentidos, com

Revista Digital do LAV - Santa Maria - vol. 8, n. 2, p. 118 - 142. - mai./ago. 2015 ISSN 1983 - 7348 http://dx.doi.org/10.5902/1983734819868 
redes de significados, com reflexões subjetivas, com assuntos nem sempre comentados. (FERRAZ, 2013)

A prática pedagógica fundamentada em paradigmas reducionistas ignora a dança como conhecimento relevante. Desse ponto de vista, se a dança é considerada mero artificio de espetáculos, sua importância como uma natureza de conhecimento é reduzida significativamente. Ou seja, a dança não se enquadra na categoria de saber científico defendida por teorias ultraracionalitas para as quais a intuição não é valiosa e nem merecedora de crédito científico.

Uma escola na qual a dança seja entendida como conhecimento, portanto como um elemento de importância para a formação dos estudantes e das estudantes, certamente não fundamentará sua compreensão sobre sujeito e sobre saberes numa perspectiva exclusivamente racionalista. Nessa escola, para a qual a dança ocupa espaço relevante na construção de saberes, a ótica intuitiva tende a ser a regente dos pensamentos e sentimentos, individuais e coletivos.

\begin{abstract}
A dança na sala de aula é mais do que a hora do lazer e do espetáculo. A dança, quando compreendida no seu bojo transdisciplinar, se torna, para o currículo praticado, tão relevante quando a matemática e a física. É importante entender que a dança, para além de saberes conceituais, evoca para a prática pedagógica, elementos atitudinais. (FERRAZ, 2013, p.16)
\end{abstract}

A compreensão de que o corpo não é um componente do ser humano completamente distante da mente e de que a mente não é mais importante do que o corpo, visto que esses dois componentes estão interpenetrados um pelo o outro, de modo que não se pode separá-los sob a alegação separatista positivista. está baseada naquilo que dissemos ao longo dos tópicos 1 e 2, quando tentamos situar o leitor sobre o ensino das artes fundamentado numa ótica intuitiva.

Considerações finais

Revista Digital do LAV - Santa Maria - vol. 8, n. 2, p. 118- 142. - mai./ago. 2015 ISSN 1983 - 7348 http://dx.doi.org/10.5902/1983734819868 
A intuição como fundamento do Ensino das Artes e a (re) criação de uma Escola Viva em tempos de revisão paradimática

Se você não estiver tomando Ritalina ou Fluxetina não será muito difícil perceber algumas cenas onde os discursos da escola objetivam capturar e obstruir a intuição em vista da formação de consumidores: "o que você vai ser quando crescer?" teria dito um adulto simpático se inclinando em direção a uma criança recém conhecida a fim de, por meio de uma pergunta como essa, demonstrar preocupação graciosa com os interesses infantis. Contudo, o adulto geralmente não percebe o peso que tal pergunta implica: uma redução de possibilidades de horizontes e de futuros. Também não é difícil rememorar alguma cena do cotidiano escolar na qual um professor, preocupado com o andamento de suas aulas, chama atenção para a importância dos estudos para seus alunos por meio da referida questão. Porém, quanto mais crescem os estudantes, e mais se aproxima o fim do período escolar, o tom da pergunta proferida pelo professor vai se tornando menos gracioso e mais ameaçador. Mas quais seriam as ameaças que progressivamente vão alterando o tom da voz deste hipotético e zeloso professor?

Talvez a ansiedade surja pela constatação de que o tempo tutoriado pelo adulto está chegando ao fim. Adiante, um tempo de responsabilidade forjado pela necessidade de ingresso no mundo do trabalho se avizinha. Tempus fugit. Sangria de um tempo vivo.

Mas se formos otimistas, acreditaremos que há uma preocupação cuidadosa em uma pergunta que quer fazer o estudante refletir acerca da responsabilidade de usar seu tempo presente (onde ele ainda não é) para se preparar para um tempo vindouro (onde ele pode vir a ser). Afinal, estudar é importante para você "ser alguém na vida!" É factível ainda que tenhamos escutando algum professor proferindo essa frase como um "bom conselho" às novas gerações. A preocupação docente talvez resida na ameaça de que os estudantes não se tornem alguém na vida. É provável que essa preocupação intergeracional seja natural e compreensível sob a ótica da preservação de nossa espécie. Todavia, é importante (e recomendável!) pensarmos quais os critérios que, em uma sociedade capitalista como a nossa, nos baseamos para reconhecermos os "alguéns" ou os "ninguéns".

Revista Digital do LAV - Santa Maria - vol. 8, n. 2, p. 118 - 142. - mai./ago. 2015 ISSN 1983 - 7348 http://dx.doi.org/10.5902/1983734819868 
Afinal, a juventude pode ser compreendida como um período da vida no qual há um excedente temporal. Trata-se de um crédito que a sociedade, por meio de suas instituições, oferece aos jovens. Essa reserva de capital simbólico é chamado por Margulis e Urresti (1996) de "moratória vital". Tal moratória consiste em "uma massa de tempo futuro, não investido, disponível de maneira diferencial segundo a classe social." (idem, p. 23)

Mas o que seria "ser alguém"? Assim, alguns zelosos professores argumentarão em tons ameaçadores da importância dos estudos para que os jovens possam num futuro próximo "competir" por um lugar no mercado. Afinal, seria por meio de um trabalho que eles teriam acesso a fontes de renda. E é o dinheiro, em última instância, que Ihes dará condições de ter acesso a bens de consumo que simbolizam sucesso na vida. Afinal, "ser alguém na vida", no presente ou no futuro, está associado, em boa parte dos discursos, aos bens de consumo que as pessoas são capazes de comprar.

Em linhas gerais, portanto, em uma sociedade capitalista, os jovens são tidos como "cheques pré-datados de vida". Não valem pelo que são, mas pelo que podem vir a ser (afinal, se "vão ser alguém na vida", é porque hoje ainda não o são!) Vale a pena se investir neles, utilizando seu excedente de tempo socialmente tolerado, para que possam "ser alguém" no futuro. Mas será que tais "cheques pré-datados de vida" terão fundo em um futuro próximo? Que fundo haveria numa proposta de compra de pacotes de felicidade, de ilhas da fantasia, de Disneylândias pasteurizadas em que o único lugar mapeável é o não-lugar dos sentidos? Até que ponto se sustenta o argumento zeloso de que o estudante deve estudar para poder ter a segurança de alcançar um lugar no mercado de trabalho que lhe dê condições de comprar uma casa (preferencialmente em um condomínio isolado) e um carro (preferencialmente blindado)? Será mesmo que podemos garantir o estigma da felicidade àqueles que muito estudaram e conseguiram, por seus méritos, empreendedorismo e esforço individuais, um emprego no qual se sentem felizardos por terem acesso a um computador e um celular que os deixarão conectados ao mundo do trabalho por aproximadamente 14 horas diárias (jornada de trabalho próxima à média do início do século $\mathrm{XX}$, antes das lutas e conquistas trabalhistas)? Trabalharão duro para adquirir um novo bem de consumo que soará essencial ao seu ritmo e estilo de vida até o próximo ano, quando uma nova versão do produto será lançada. Assim, o

Revista Digital do LAV - Santa Maria - vol. 8, n. 2, p. 118- 142. - mai./ago. 2015 ISSN 1983 - 7348 http://dx.doi.org/10.5902/1983734819868 
excesso de trabalho e atividades darão ao bem sucedido trabalhador a sensação de que o ano passa cada vez mais rápido e que a vida lhe foge pelos dedos...

Em sua obra "A fábrica da infelicidade" (2005, p.5), o sociólogo italiano Franco Berardi Bifo afirma:

Nos últimos anos, todos começaram a se dar conta de que o neoliberalismo não é o mais perfeito dos sistemas políticos, de que o mercado não se corrige por si só, e de que a mão invisível de influência smithiana não é capaz de regular os processos sociais e financeiros até produzir uma perfeita autoregulação do ciclo econômico. Ficou evidente que a infoprodução não é esse reino da felicidade e da autorealização que a ideologia havia prometido como prêmio aos que trabalham na economia da rede, nas condições de contínuo estresse competitivo da empresa fractal individualizada. A promessa de felicidade e auto-realização no trabalho estava implícita no edifício discursivo e imaginário da new economy. Esta promessa se debilitou: a crise financeira das ações tecnológicas fez estourar um mal-estar que até esse momento foi omitido e acalmado com doses massivas de substâncias - financeiras e psicotrópicas. Esse mal-estar não teve como se manter ocultado ao ficar claro que os investimentos diminuíam e, com isso, desapareceria o incentivo para adiar toda reflexão, todo relaxamento e todo aprofundamento.

O fato é que basta uma olhadela a nossa volta para perceber que a lógica do modo de vida capitalista contemporâneo tem gerado um mundo dividido entre poucos alguéns e uma multidão de ninguéns. Todos vorazmente desejosos em consumir um mundo cujo sua natureza não dá mais conta em se renovar. E tal postura antropocêntrica e egocentrada ameaça cotidianamente inúmeras formas de vida sobre o planeta. Inclusive as vidas humanas.

Uma outra forma de pensar sobre "ser alguém" seja refletir um pouco sobre seu avesso: "os ninguéns". De forma forte e poética, o poeta uruguaio Eduardo Galeano, em seu "Livro dos Abraços" (2002, p.42) versa sobre estes:

Os Ninguéns

Revista Digital do LAV - Santa Maria - vol. 8, n. 2, p. 118 - 142. - mai./ago. 2015 ISSN 1983 - 7348 http://dx.doi.org/10.5902/1983734819868 
As pulgas sonham com comprar um cão, e os ninguéns com deixar a pobreza, que em algum dia mágico a sorte chova de repente, que chova a boa sorte a cântaros; mas a boa sorte não chove ontem, nem hoje, nem amanhã, nem nunca, nem uma chuvinha cai do céu da boa sorte, por mais que os ninguéns a chamem e mesmo que a mão esquerda coce, ou se levantem com o pé direito, ou comecem o ano mudando de vassoura.

Os ninguéns: os filhos de ninguém, os donos de nada.

Os ninguéns: os nenhuns, correndo soltos, morrendo a vida, fodidos e mal pagos:

Que não são, embora sejam.

Que não falam idiomas, falam dialetos.

Que não praticam religiões, praticam superstições.

Que não fazem arte, fazem artesanato.

Que não são seres humanos, são recursos humanos.

Que não tem cultura, têm folclore.

Que não têm cara, têm braços.

Que não têm nome, têm número.

Que não aparecem na história universal, aparecem nas páginas policiais da imprensa local.

Os ninguéns, que custam menos do que a bala que os mata.

Ser um "Ninguém" é não ser. Tornar-se um "ninguém" é, portanto, tornar-se um invisível. Assim, para ser procura-se "parecer". Martin Buber (2014, p.141) afirma que "a verdadeira problemática no âmbito do inter-humano é a dualidade do ser e do parecer." Geralmente, essas duas espécies de existência se apresentam sob a forma de uma mistura. Ambas possuem legitimidade ontológica. São legítimas e autênticas, pois sempre somos e parecemos ser. Afinal, existimos porque somos, mas existimos também porque parecemos ser. O problema reside quando parecemos ser algo que não somos. Aí, se perde a oportunidade de relações autênticas e encontros verdadeiros entre "Eu e Tu" (idem, p.143).

Isso fica evidente em nossas relações. Se nossa existência se sustenta mais na busca por parecer do que na busca por ser dificilmente conseguiremos ser com os outros. Dessa forma, objetificamos o Outro. Objetificamos as pessoas. Objetificamos a natureza.

Em um sentido mais amplo e histórico podemos inferir que nossa civilização produziu uma dinâmica na qual reduziu todos os seres (inclusive o ser humano!) à condição de objetos. De maneira especial, a partir da modernidade, o ser humano, tomado 
por uma busca desenfreada por poder e controle, ungiu-se enquanto senhor da natureza. Ao buscar dominar a vida e sugar dela seu infindável desejo de lucro o ser humano desvitalizou-se.

Carolyn Merchant (1980, p.17), em sua obra "The Death of nature" demonstra como:

ao investigarmos as raízes de nosso atual dilema ambiental e suas conexões com a ciência, a tecnologia e a economia, cumpre-nos reexaminar a formação de uma visão do mundo e de uma ciência que, ao reconceituar a realidade mais como uma máquina do que como um organismo vivo, sancionou a dominação da natureza e das mulheres. Têm que ser reavaliadas as contribuições de tais "patriarcas" da ciência moderna como Francis Bacon, Willian Harvey, René Descartes, Thomas Hobbes e Isaac Newton.

Ou seja, o humanismo moderno é impregnado de um pensamento antropocêntrico, egocentrado e onipotente que justifica as ações de objetificação das formas de vida sobre o planeta. Esse pensamento reducionista está relacionado a um "empobrecimento do próprio ser humano, um estreitamento de suas potencialidades de sensibilidade, percepção e pensamento." (UGER, 2006, p.162)

Quando examinamos, portanto, a zelosa e infrutífera hipotética pergunta do professor com mais cuidado diluiremos sua culpa. A crise de sua aula faz parte de uma crise cultural muito mais ampla. Temos usado modelos conceituais obsoletos e variáveis irrelevantes para compreender uma mudança de paradigma em curso. A crise atual não é uma crise de indivíduos ou instituições sociais. É uma transição de dimensões planetárias, antropogênicas, inclusive. "Como indivíduos, como sociedade, como civilização e como ecossistema planetário, estamos chegando a um momento decisivo." (CAPRA, 2001, p.30).

Em suma, além de refletirmos sobre ser "alguém" ou "ninguém", urge discutirmos o que entendemos por "vida"? Qual o alcance do sentido que dou para aquilo que é vivo? Será que percebo que o vivo somente se mantém vivo na com-vivência? Até que ponto percebo que faço parte de uma grande "teia da vida"? Afinal de contas, a crise da Educação está contida também em uma crise Cultural. A cultura está para os humanos como a teia de aranha está para as aranhas. A teia é produto da aranha

Revista Digital do LAV - Santa Maria - vol. 8, n. 2, p. 118 - 142. - mai./ago. 2015 ISSN 1983 - 7348 http://dx.doi.org/10.5902/1983734819868 
ou a aranha é produto da teia? Até que ponto não somos também partejados por aquilo que nossa teia emaranha? Num primeiro momento podemos inferir que a teia é produto da aranha, como de fato o é. Todavia, ao produzir a teia e dela depender para se movimentar, caçar e com-viver a aranha se torna produto da teia que ela mesma produziu. Assim também é a cultura para os humanos. Herdamos uma teia de sentidos e símbolos que nos enreda e nos prende. Todavia, podemos criar novas formas de tecer sentido e existência. Mas é claro que também nos tornaremos produto daquilo que produzimos.

Assim, todo espaço educativo vivo intrinsicamente traz consigo a crise de preservar os modos de vida que nos enlaçam, sustentam e prendem. Pois, ao mesmo tempo, é pela educação que podemos recriar nossa cultura, oferecendo outros enlaces. Todavia, como criar novas teias de significado que respeitem a teia da vida da qual somos apenas mais um entrecruzar de caminhos (bifurcações desse elán vital) dentre tantas mãos que tecem a possibilidade dos encontros?

Oxalá saibamos deixar o Elan Vital fluir por meio da Intuição em nossos modos de produzir conhecimentos em uma escola viva. De nossa parte, seguiremos estudando, pesquisando sobre este tema tão instigante e potente.

\section{Referências}

BERGSON, Henri. A Evolução Criadora. São Paulo: Martins Fontes, 2009.

BERGSON, Henri. A Intuição Filosófica. Lisboa: Colibri, 1994.

BIFO, F. A fábrica da infelicidade: trabalho cognitivo e a crise da new economy. Rio de Janeiro: DP\&A, 2005.

BIFO. Generación Post-Alfa: patologías e imaginarios en el semiocapitalismo. Buenos Aires: Tinta Limón, 2007.

BUBER, M. Do diálogo e do dialógico. São Paulo: Perspectiva, 2014.

CAPRA, F. O Ponto de Mutação: a ciência, a sociedade e a cultura emergente. São Paulo: Cultrix, 2001.

Revista Digital do LAV - Santa Maria - vol. 8, n. 2, p. 118- 142. - mai./ago. 2015 ISSN 1983 - 7348 http://dx.doi.org/10.5902/1983734819868 
CASTORIADIS, Cornelius. A instituição imaginária da sociedade. Rio de Janeiro, Paz e Terra, 2007.

DELEUZE, Gilles. Bergsonismo. São Paulo: Editora 34, 1999.

DEMO, Pedro. Complexidade e Aprendizagem. São Paulo, Atlas Editora, 2010.

ENGUITA, Mariano Fernández. Educar em Tempos incertos. Porto Alegre: ARTMED, 2007.

FERRAZ, Rianne. Reflexão sobre a dança na escola: o caso da rede privada. Maceió, Edição do Autor, 2013.

GALEANO, Eduardo. O Livro dos Abraços. Porto Alegre: L\&PM, 2002

HUIZINHA, Johan. Homo Ludens. São Paulo, Editora Perspectiva. 2000.

MACHADO, Alexsandro dos Santos. Intuições para uma Pedagogia da Intuição: a amizade enquanto uma Experiência Integral pela Dinâmica das Cartas. Tese de Doutorado. Universidade Federal do Rio Grande do Sul, Porto Alegre, 2012.

MACHADO, Alexsandro dos Santos. Intuições para uma Pedagogia da Intuição no Ensino Médio: a Duração e os Sentidos da Educação por meio da Dinâmica das Cartas. Revista Matéria-Prima, Práticas Artísticas no Ensino Básico e Secundário. ISSN 2182-9756. Vol 1 (1): 37-45, 2013.

MAFFESOLI, Michel. Elogio da Razão Sensível. Petrópolis: Vozes, 2005.

MARGULIS, M.; URRESTI, M. La juventud es más que una palabra. Buenos Aires: Biblos, 1996.

MERCHANT, C. The Death of Nature. New York: Harper \& Row, 1980.

MORIN, Edgar. A inteligência da Complexidade. São Paulo: Peirópolis, 2000.

NEVES, Maria do Céu Patrão. Tradução, introdução e notas. In: BERGSON, H. A Intuição Filosófica. Lisboa: Colibri, 1994.

Revista Digital do LAV - Santa Maria - vol. 8, n. 2, p. 118 - 142. - mai./ago. 2015 ISSN 1983 - 7348 http://dx.doi.org/10.5902/1983734819868 
NUNES, Clarice. Cultura escolar, modernidade pedagógica e política educacional no espaço urbano carioca. In: HERSCHAMNN, Micael; KROPF, Simone; NUNES, Clarice. Missionários do Progresso: médicos, engenheiros e educadores no Rio de Janeiro (1870-1937). Rio de Janeiro: Diadorim, 1996.

RODARI, Gianni. Gramática da Fantasia. São Paulo: Summus, 1982.

SOUZA, Rosa de Fátima de. Templos de civilização: um estudo sobre a implantação dos grupos escolares no estado de São Paulo: 1880-1910. Campinas: Mercado das Letras, 2009.

STRAZZACAPA, Márcia. Dança na Educação discutindo questões básicas e polêmicas. Revista Pensar a Prática, v.6, p. 73-85, 2002/2003.

UGER, N.M. Heidegger: "salvar é deixar-ser". In BRASIL. Bases Filosóficas para a Educação Ambiental. Brasília: Ministério da Educação, UNESCO, 2006.

VALDEMARIN, Vera Teresa. O liberalismo demiurgo: estudo sobre a Reforma Educacional projetada nos pareceres de Rui Barbosa. São Paulo: Cultura Acadêmica, 2000.

VALDEMARIN, Vera Teresa. Estudando as lições de coisas. Campinas: Autores Associados, 2004.

VALDEMARIN, Vera Teresa. O método intuitivo: os sentidos como Janelas e Portas que se Abrem para um Mundo Interpretado. In: SAVIANI; ALMEIDA; SOUZA; VALDEMARIN. O Legado Educacional do Século XIX. Campinas-SP: Autores Associados, 2014a.

VALDEMARIN, Vera Teresa. Os sentidos e a Experiência: professores, alunos e métodos de ensino. In: SAVIANI; ALMEIDA; SOUZA; VALDEMARIN. O Legado Educacional do Século XX no Brasil. Campinas-SP: Autores Associados, 2014b.

VALDEMARIN, Vera Teresa; TEIVE, Gladys Mary Ghizoni; HAMDAN, Juliana Cesário. Modernidade metodológica e pedagógica. apropriações de método de ensino intuitivo nas reformas da instrução pública de Minas Gerais, Santa Catarina e São Paulo (1906-1920): ideias e práticas em movimento. In: SOUZA, Rosa 
Fátima de; SILVA, Vera Lúcia Gaspar da; SÁ, Elizabeth Figueiredo de (Org.). Por uma teoria e uma história de escola primária no Brasil: investigações comparadas sobre a escola graduada (1870-1930). Cuiabá: EdUFMT, 2013

VEIGA, Cynthia Greive. Educação estética para o povo. In: FARIA FILHO; VEIGA; LOPES. 500 anos de educação no Brasil. Belo Horizonte: Autêntica, 2000.

i Professor Adjunto da Universidade Federal de Pernambuco. Tem experiência na área de Educação e Psicologia, com ênfase em Formação de Educadores, atuando principalmente nos seguintes temas: Educação Popular em Saúde, Educomunicação e Relações Étnico-Raciais na Escola, Pedagogia da Intuição, Memória e Educação em Bergson, História Oral e Histórias de Vida.

ii Professor Adjunto da Universidade Federal Rural de Pernambuco. Tem experiência nos estudos sobre transdisciplinaridade, direitos humanos da infância e da juventude, formação de leitores infantis e juvenis e prática pedagógica com crianças e adolescentes. E escritor e atua como professor permanente no Programa de PósGraduação em Educação, Culturas e Identidades (UFRPE/FUNDAJ) e como professor colaborador no Programa de Pos-Graduacao em Educação da UPE (FPNM/UPE). Lidera o GETIJ - Grupo de Estudos da Transdisciplinaridade, da Infância e da Juventude.

Recebido em: 07 de maio de 2015.

Aprovado em: 19 de julho de 2015.

Revista Digital do LAV - Santa Maria - vol. 8, n. 2, p. 118 - 142. - mai./ago. 2015 ISSN 1983 - 7348 http://dx.doi.org/10.5902/1983734819868 